\title{
Gradient Mapping of Pattern Ground Characteristics from a Photomosaic of the IBP Tundra Biome Site near Barrow, Alaska ${ }^{1}$
}

\author{
S. I. Outcalt ${ }^{2}$
}

An air photographic mosaic covering an area of $44.5 \times 10^{5} \mathrm{~m}^{2}$ was subdivided into 741 rectangular cells $(60 \times 100 \mathrm{~m})$. Pattern frequency, center relief, shape, and wedge image clarity were tabulated using three states for each character on a nominal scale. These state variables were converted to an interval scale by the application of a spatial smoothing filter. The new values were subjected to a principal components analysis which indicated that a parsimonious classification of pattern spatial variation could be constructed by equally weighting the first three nominal variables (frequency, relief, shape). The maps derived from this scheme indicate the areas on the tundra surface where polygon evolution may be occurring at the present time. KEY WORDS: mapping, Markov processes, principal components analysis, geomorphology.

\section{INTRODUCTION}

The use of air photography in geomorphic studies may be constrained because much of the easily accessible information is available in the form of character states on a nominal scale. It is, however, impossible to map gradients in geomorphic nominal information. However, this process may be critical in hypothesis formation. A typical example of such a character would be rock glacier surface material shape. An analysis could be designed to measure three shape character states [(1) angular; (2) transitional; (3) rounded]. Measurements on a ranked or interval scale would create the necessity for making geometric measurements on individual boulders in the photography and thus increase the data collection work load by some orders of magnitude.

Geomorphologists traditionally have failed to exploit nominal data with the notable exception of J. T. Andrews who, in collaboration with G. Estabrook, a biomathematician, produced an extremely creative paper on the processing and analysis of geomorphic nominal data (Andrews and Esta-

${ }^{1}$ Manuscript received 6 July 1973.

${ }^{2}$ Geography Department, University of Michigan (USA). 
brook, 1971). The analysis here is somewhat simpler as the variables beneath character states are assumed to be continuous.

Geomorphic photo data are used to aid in the design of a critical field experiment or to support some argument linking spatial form variation to process. In this paper a data set of four geomorphic characters having three states each will be analyzed assuming that the characters are continuous through the transitional state on an interval scale. If data are mapped as a function character state in cellular space the map is a matrix and the matrix a map. This simple relationship opens fascinating possibilities for the analysis and display of spatial data sets (see Tobler, 1967).

\section{THE DATA SET}

The data set is comprised of four $39 \times 19$ matrix maps covering the photomosaic area with rectangular cells $(60 \times 100 \mathrm{~m})$. Only a $20 \mathrm{~m}$ strip along the southern and eastern margins of the photomosaic was excluded from the grid area as the origin of the network was in the north-west corner. The rectangular cellular network was employed to yield conformal maps on a computer line printer from stored matrix data. The raw data set structure is outlined in Table 1, and the photomosaic image is Figure 1.

Each character state was evaluated in each of the 741 cells on the photomosaic. This process was rapid and included qualitative spatial averaging within the cells. These data were used to generate a data set on an interval scale by spatially smoothing the interior cell values with a two-dimensional, normal filter employing the same weights as Tobler (1967). The smoothed interval data sets are presented in block diagram form in Figure 2.

\section{MARKOV TRANSITION MATRICES OF NOMINAL CHARACTER SETS}

The transitions between states were tallied along rows from west to east omitting jumps between columns using a modified version of an algorithm presented by Harbaugh and Bonham-Carter (1970). These calculations yielded the transition matrices presented as Table 2.

\section{Table 1. Raw Nominal Data Set}

\begin{tabular}{|c|c|}
\hline Character & States (coded: $1,2,3$ ) \\
\hline Pattern frequency & low (L.T. 15/cell), transitional, high (G.T. 25/cell) \\
\hline Center relief & low, transitional, high \\
\hline Shape & rectangular, transitional, polygonal \\
\hline Wedge image & sharp, transitional, blurred \\
\hline
\end{tabular}




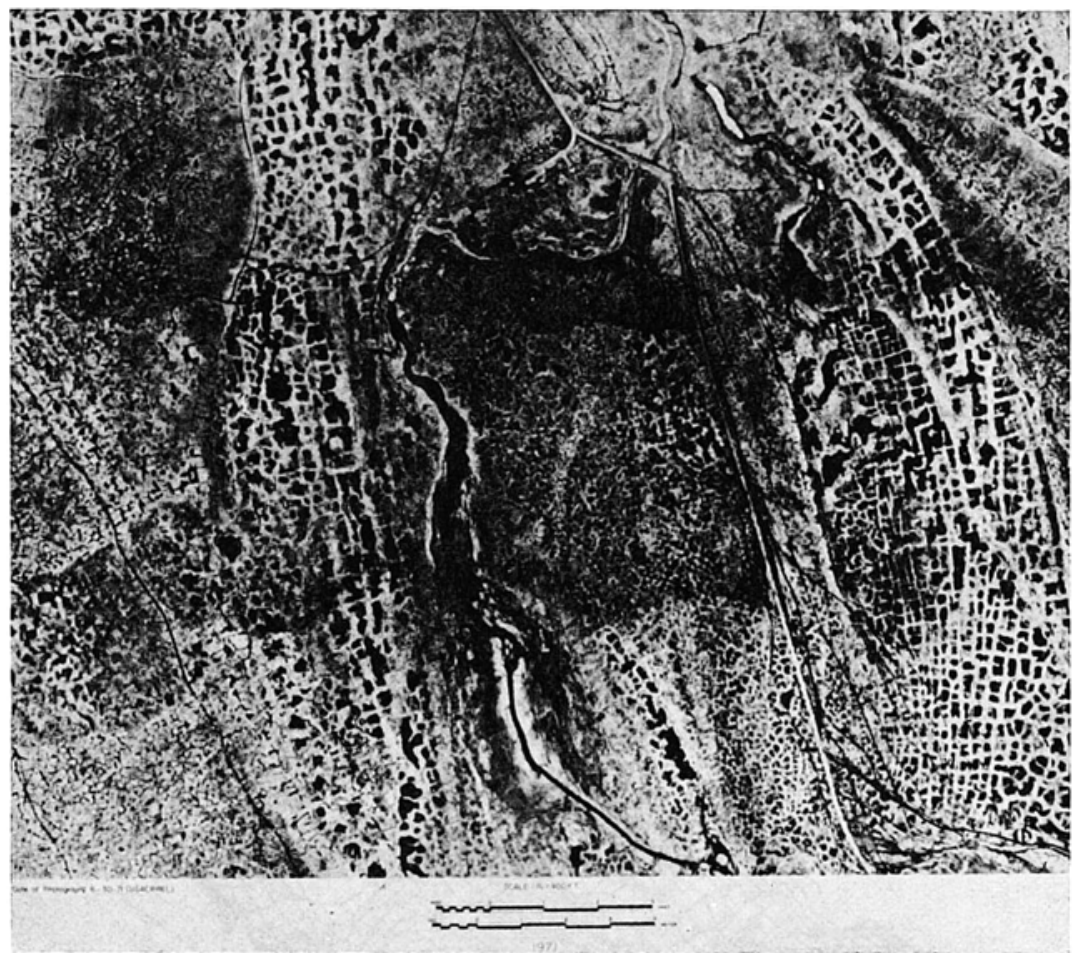

Figure 1. Photomosaic of U.S. Tundra Biome sites near Barrow, Alaska. Area $44.5 \times 10^{5} \mathrm{~m}^{2}$.

All transitions exhibit strong diagonal values indicating spatial autocorrelation and low probabilities for moves between extreme states. This latter characteristic confirms the assumption that the characters are continuous beneath the nominal state classifications. An examination of the mosaic photograph indicates that extreme state transitions should approach zero if the cell size were reduced toward a limit of zero. The low, although finite, probabilities for transitions between extreme states may be an artifact of rather large cell size $\left(6 \times 10^{4} \mathrm{~m}^{2}\right)$.

\section{CORRELATION WITHIN THE CONTINUOUS CHARACTER DATA SET}

The interval scale data set yielded the correlation coefficient matrix presented in Table 3. 

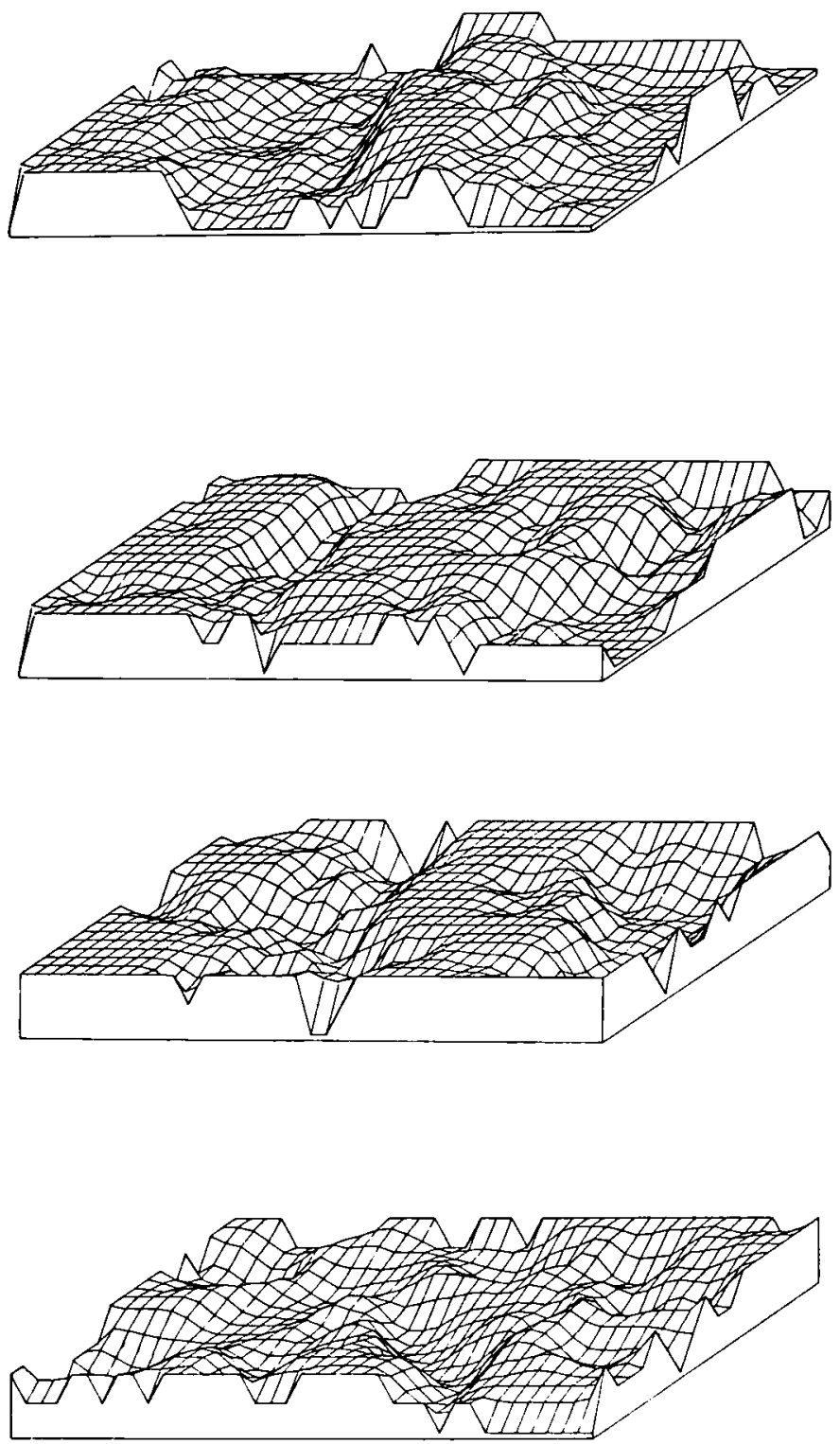

Figure 2. Smoothed data sets. Top to bottom: frequency, relief, shape, and wedge image.

The correlation matrix indicates that there is a high degree of shared information in the continuous variable data set, particularly among the first three variables. Further insight into the structure of this information sharing 
Table 2. Transition Probability Matrices

\begin{tabular}{|c|c|c|c|}
\hline \multicolumn{4}{|c|}{ Pattern frequency; states: (1) low, (2) trans., (3) high } \\
\hline To state $\rightarrow$ & 1 & 2 & 3 \\
\hline From state $\downarrow 1$ & 0.78 & 0.18 & 0.04 \\
\hline 2 & 0.34 & 0.48 & 0.18 \\
\hline 3 & 0.05 & 0.21 & 0.75 \\
\hline
\end{tabular}

Center relief; states: (1) low, (2) trans., (3) high

\begin{tabular}{rccc} 
To state $\rightarrow$ & 1 & 2 & 3 \\
\hline From state $\downarrow 1$ & 0.69 & 0.22 & 0.09 \\
2 & 0.20 & 0.51 & 0.29 \\
3 & 0.03 & 0.13 & 0.84
\end{tabular}

Shape; states: (1) rectangular, (2) trans., (3) polygonal

\begin{tabular}{rccc}
\multicolumn{1}{l}{ To state $\rightarrow$} & 1 & 2 & 3 \\
\hline From state $\downarrow 1$ & 0.68 & 0.21 & 0.11 \\
2 & 0.22 & 0.46 & 0.32 \\
3 & 0.05 & 0.09 & 0.86
\end{tabular}

Wedge image; states: (1) sharp, (2) trans., (3) blurred

\begin{tabular}{rccc} 
To state $\rightarrow$ & 1 & 2 & 3 \\
\hline From state $\downarrow 1$ & 0.68 & 0.22 & 0.10 \\
2 & 0.11 & 0.71 & 0.18 \\
3 & 0.03 & 0.24 & 0.73
\end{tabular}

system may be gained by performing a principal components analysis on the continuous variables (Davis, 1973).

\section{PRINCIPAL COMPONENTS ANALYSIS OF CONTINUOUS CHARACTER VARIABLES}

The correlation coefficient matrix was used as input for a principal components analysis of the continuous variable set. This analysis yielded the results reported in Table 4.

The first two eigenvectors were mapped and presented as pin diagrams in 
Table 3. Correlation Coefficient Matrix-Continuous Data Set

\begin{tabular}{lrlrr}
\hline & Freq. & Relief & Shape & Wedge \\
Freq. & 1.00 & & & \\
Relief & 0.58 & 1.00 & & \\
Shape & 0.64 & 0.55 & 1.00 & \\
Wedge & -0.25 & $0.03^{\sigma}$ & -1.00 & 1.00 \\
\hline
\end{tabular}

${ }^{\circ}$ not sig. at 0.99 level

Table 4. Tabulation of Principal Components Analysis Results

\begin{tabular}{lcccr}
\hline Eigenvector & I & II & III & \multicolumn{1}{c}{ IV } \\
Variance & 55 & 26 & 11 & 8 \\
Accumulated variance & 55 & 81 & 92 & 100
\end{tabular}

Variable Loadings on Eigenvectors

\begin{tabular}{ccccc} 
Eigenvector & Frequency & Relief & Shape & Wedge image \\
I & -0.59 & -0.54 & -0.57 & 0.15 \\
II & 0.11 & -0.30 & -0.09 & -0.94 \\
III & 0.08 & 0.73 & -0.65 & -0.18 \\
IV & 0.79 & -0.29 & -0.49 & 0.23 \\
\hline
\end{tabular}

Figure 3. Note that there is a strong equal weighting of the first three variables (underlined in Table 4) on the first eigenvector accounting for 55 percent of the total variance in the data set. This suggests that the influence of the wedge image variable is not a strong contributor to the major pattern of spatial variation and is in fact anisomorphic to that pattern. The analysis was rerun omitting the wedge image variable and again eigenvector I loadings of frequency, relief, and shape were nearly equal $(-0.59,-0.56,-0.58)$ and accounted for 73 percent of the spatial variance in the reduced data set. The first principal component (eigenvector I) yields its lowest values on small (high frequency), high-centered, polygonal patterns and yields highest scores on large (low frequency), low-centered, rectangular features. This general pattern is emphasized on the photomosaic. However, it is nearly impossible to determine the spatial gradient from one pure type to the other using qualitative techniques. Quantitative formulations at least have the advantage of permitting investigators to make their errors in analytical formulation 

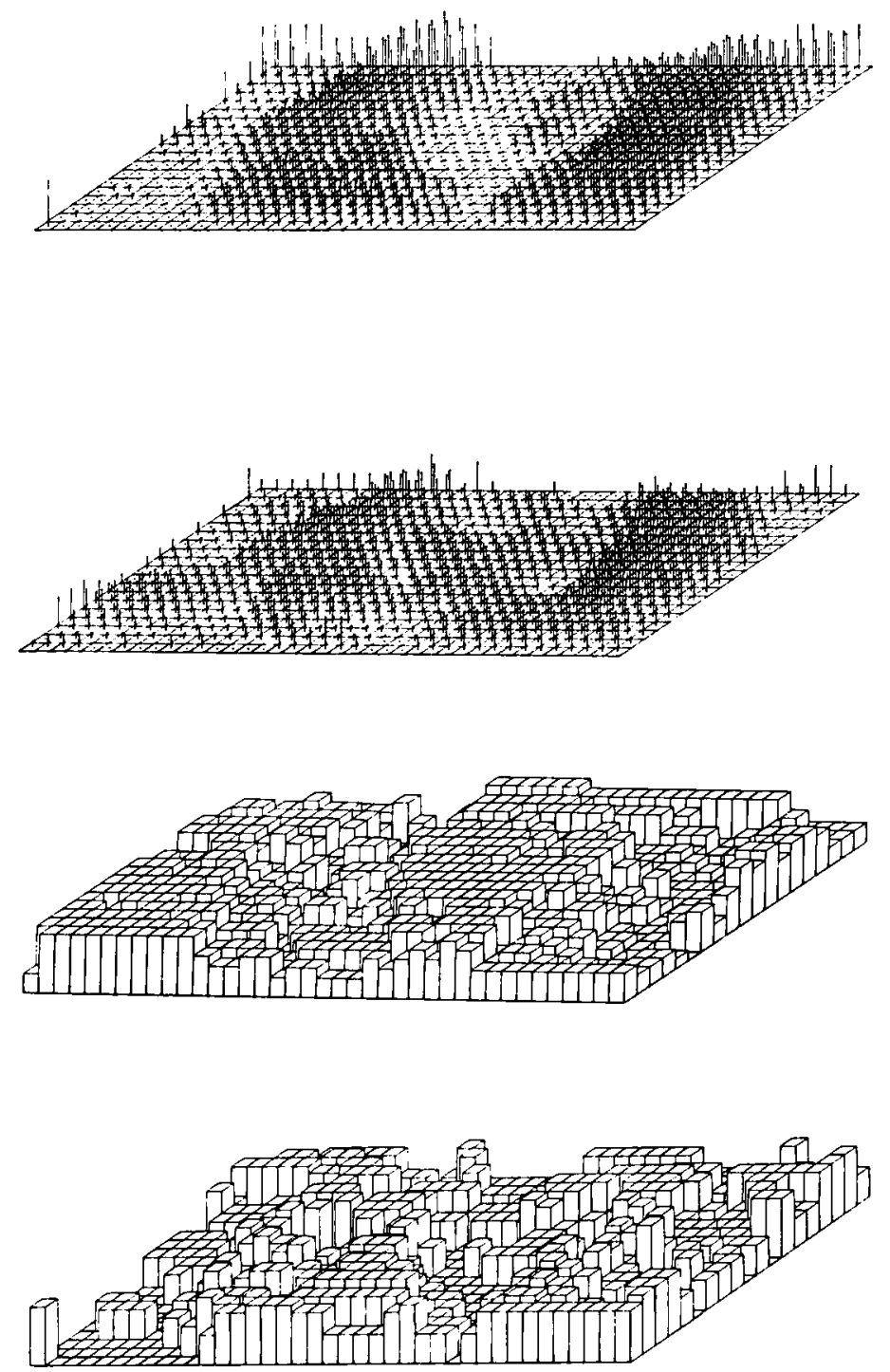

Figure 3. Pin diagrams of PC1 and PC2. Histograms of $P_{l}$ and $I_{\mathrm{d}}$ (see text for additional information). Top to bottom: map of PC1, map of PC2, mapping of pattern classification, and mapping of cell classification distance.

spatially catholic. The principal components analysis indicated that simple combination of the raw nominal data set state variables might yield a parsimonious classification system for the regionalization of the map space 
which should indicate the direction and relative magnitude of environmental gradients.

\section{PATTERN REGIONALIZATION}

Two new spatial variables were constructed from the nominal coding notation listed in Table 1, using the cellular states codes of Frequency $(F)$, Relief $(R)$, and Shape $(S)$. These were named the Pattern Index $\left(P_{i}\right)$ and the Index Distance $\left(I_{d}\right)$ being calculated for each cell by the simple rules presented in eqs (1) and (2).

$$
\begin{gathered}
P_{i}=(F+S+R) / 3 \\
I_{d}=\sqrt{ }\left[(F-S)^{2}+(S-R)^{2}+(F-R)^{2}\right]
\end{gathered}
$$

The first variable $\left(P_{i}\right)$ will yield the value 1 for large, low-center, rectangular features and the value 3 for small, high-center polygons. The second variable $\left(I_{d}\right)$ will be zero in pure-type locations and reach a value of $\sqrt{ } 12$ in the situation of maximum variation between the nominal state characters. These new classificatory spatial variables were mapped and are displayed as two-dimensional histograms in Figure 3.

This technique can be extended to data spaces having any number of dimensions and can be employed with variable weighting should the eigenvector loadings suggest this course. Lastly, the Markov transition matrix for the pattern index should be calculated from a truncated form of the index to see if the high degree of spatial autocorrelation and low-transition probabilities between extreme states are preserved in the patters index variable $\left(P_{i}\right)$. Truncation was accomplished by scoring all values on a scale (0-99) and assigning a nominal, 1 , to those less than 25 ; a nominal, 3 , to those greater than 75 , and a nominal, 2 , to transitional values. This allowed a disparity of only 1 state variable to the transitional state for extreme type classification. The resulting transition probability matrix is presented as Table 5 .

The spatial autocorrelation and transition probabilities for transitions between 'pure types' have been preserved in the regionalization process.

\begin{tabular}{|c|c|c|c|}
\hline To state $\rightarrow$ & 1 & 2 & 3 \\
\hline From state $\downarrow 1$ & 0.68 & 0.29 & 0.03 \\
\hline 2 & 0.13 & 0.72 & 0.15 \\
\hline 3 & 0.01 & 0.18 & 0.81 \\
\hline
\end{tabular}

Table 5. Pattern Index Transition Matrix 


\section{UTILIZATION OF PATTERN MAPS}

The initial goal of the study was the exploration of a regionalization strategy. However, it is obvious that the 'pure type' locals are related to broad geomorphic genetic classifications. The large, low-centered, rectangular features are located in old lake beds whereas the small, high-centered polygons are concentrated on rolling upland surfaces. Mapping the pattern index and index distance focus attention on areas in old lake basins where large, low-centered, rectangular features are seemingly being subdivided by radial cobweb networks of new wedges centered on wet circular areas at the center of the rectangular features. Lastly, on inspection of the upland surfaces there are indications of old, rectangular, low-frequency wedges with orthogonal junctions now hidden amongst high-density, small, high-center, polygonal features.

This analysis strongly suggests that pattern mapping in conjunction with detailed geomorphic mapping (e.g., Sellman and others, 1972) and Lachenbruch's (1962) thermal contraction analysis along moisture gradients produced by drainage network consolidation and climate change may yield a general field theory of polygon evolution.

\section{CONCLUSIONS}

This analysis establishes the following characteristics of the pattern ground at Barrow.

(1) Two general pure types exist:

(a) Large, low-center, rectangular features;

(b) Small, high-centered polygons.

(2) Direct spatial transition between pure types is statistically unlikely and may be prohibited in reality, a transitional state being necessary for the spatial change of state.

To this information add:

(3) The two type locations dry upland (small, high polygons) and old lake basins (large, low, rectangular) clearly lie along a moisture gradient.

And infer:

(4) The transition zone may sweep across the tundra through time occupying transitional zones along surface moisture gradients produced by drainage network evolution and climatic change as it influences drainage and active layer evolution.

\section{ACKNOWLEDGMENTS}

The author is indebted to Prof. W. Tobler of the University of Michigan for 
stimulating his interest in cellular geography and to Dr. P. Webber of the Institute of Arctic and Alpine Research, University of Colorado, for reviewing a draft manuscript at Barrow.

The computer graphics programs were written at the Department of Geography, University of Michigan, by Frank Rens under the direction of Prof. Tobler. The standard statistical analysis was run using the facilities of the Statistical Research Laboratory of the University of Michigan. This research was funded by the NSF IBP Tundra Biome Grant to the University of Alaska-Project 3742, "Geomorphic description and modeling of nearsurface regimes."

\section{REFERENCES}

Andrews, J. T., and Estabrook, G., 1971, Application of information and graph theory: Jour. Geology, v. 79 , no. 2, p. 207-221.

Davis, J. C., 1973, Statistics and data analysis in geology: John Wiley \& Sons, Inc., New York, $556 \mathrm{p}$.

Harbaugh, J. W., and Bonham-Carter, G. F., 1970, Computer simulation in geology: Wiley Interscience, New York, $575 \mathrm{p}$.

Lachenbruch, A. H., 1962, Mechanics of thermal contraction cracks and ice-wedge polygons in permafrost: Geol. Soc. America Sp. Paper 70, 69 p.

Sellmann, P. V., Carey, K. L., Keeler, C., and Hartwell, A. D., 1972, Terrain and coastal conditions on the Arctic Alaskan coastal plain: USA-CRREL, Sp. Rep. 165, Hanover, New Hampshire, 79 p.

Tobler, W. R., 1967, Of maps and matrices: Jour. Regional Sci. (supp.), v. 7, no. 2, p. 275-280. 